\title{
EL OCÉANO DE FRONTERAS INVISIBLES: RELECTURAS HISTÓRICAS SOBRE (¿EL FIN?DE) LA ESCLAVITUD EN LA NOVELA CONTEMPORÂNEA, DE DAIANE NASCIMENTO SANTOS \\ EL OCÉANO DE FRONTERAS INVISIBLES: RELECTURAS HISTÓRICAS SOBRE (¿EL FIN?DE) LA ESCLAVITUD EN LA NOVELA CONTEMPORÂNEA,BY DAIANE NASCIMENTO SANTOS
}

\author{
Vanessa Riambau PInheiro*
}

livro El océano de fronterasinvisibles: relecturas históricas sobre (¿elfin?de) laesclavitudenla novela contemporánea, publicado, em 2015, pela doutora em Estudos Americanos, Daiana Nascimento dos Santos, é um promissor estudo acerca das relações entreliteratura e história a partir da análise das diferentes conotações que a escravidão assumiu na ficção. A escravidão, que "se evidenciou como uma das engrenagens do sistema econômico da época, legitimando-se neste panorama pela prática da violência em suas diversas acepções e simbologias em mais de cinco séculos de existência" (SANTOS, 2015, p. 35, tradução nossa), é verificada através de diferentes contextos e simbologias. Entretanto, a obra não apenas viceja este tema já tantas vezes abordado, mas o faz desde narrativas cuja voz é do sujeito histórico marginalizado, aquele a quem pouco temos a oportunidade de ouvir. Ao darem a voz aos subalternizados pelos discursos hegemônicos de poder e opressão, as obras adquirem um relevante papel de reconfiguração do discurso oficial e de validação do protagonismo negro, ademais de permitirem o deslocamento do foco do eixo eurocêntrico,a fim de se problematizar o conflito escravocrata e suas consequências a partir de outro locus de enunciação. Destarte, ademais da temática afim e do lugar social do

*Professora Adjunta de Literaturas Portuguesa e Africana na Universidade Federal da Paraíba (UFPB). 
sujeito discursivo, o fio condutor que une estas histórias é a busca coletiva da(s) identidade(s)negro africana(s), vista(s) como uma conquista obtida através de um duro e lento processo histórico marcado pela violação e pela resiliência.

A autora, brasileira radicada no Chile, promove uma reflexão acerca das relações entre a escravidão e a representação imagética da África na América Latina enquanto locus histórico, físico ou utópico onde se projetam não só a escravatura, mas também suas implicações sociais, como a diáspora, a resistência, a luta social e a afirmação identitária e cultural negroafricana.

A pesquisa foi realizada através da análise de quatro romances que versam sobre o assunto sob distintas perspectivas (Angola; Cuba; Colômbia; Brasil), respectivamente: A gloriosa família: o tempo dos flamengos(1997), de Pepetela; O reino deste mundo (1949), de Alejo Carpentier,Changó, el gran putas (1982), de Manuel Zapata Olivella eUm defeito de cor (2006), de Ana Maria Gonçalves. ${ }^{1}$ O corpus citado (três de origem latinoamericana e um africano) foi escolhido por sua cronologia diegética: desta forma, o período é encetado na África do século XVII, passa pelo Caribe no final do século XVIII, no período da Revolução Haitiana, e termina no século XIX na América Latina e na África. Cabe salientar que o estudo não trata apenas de estabelecer um paradigma literário, mas de expandir este espectro além do âmbito ficcional e de problematizar a questão social a fim de ampliar a discussão ao contexto pós-colonial e suas repercussões na contemporaneidade.

Neste sentido, a memória oral ganha relevância dentro das narrativas, pois atua como mecanismo de resistência à opressão social e à aculturação imposta pelo colonizador.O resgate desta memória aparece em A gloriosa família: o tempo dos flamengos representada pela pemba, instrumento de perpetuação da reminiscência. Na trama de Pepetela, o narrador assume o papel de validação da tradição oral africana como um mecanismo importante para a conservação da história. Enquanto alegoria do silenciamento relegado aos negros na história oficial, o narrador apresenta-se mudo, representando o sujeito marginalizado que se reveste da autoridade coletiva de um protagonismo possível dentre os esquecidos e excluídos pela sociedade.

Ambientada em Angola no contexto escravagista do século XVII, a obra propõe uma releitura da ocupação holandesa em Angola, entre os anos de 1642 e

\footnotetext{
${ }^{1}$ As datas mencionadas se referem ao ano da 1 a edição das obras.
} 
1648, a partir da saga familiar dos Van Dum. A história destaca o país africano como cenário singular que vem a se tornar uma das principais rotas do comércio transatlântico, desempenhando um papel fundamental na manutenção da prática e disseminação do tráfico escravagista. Entretanto, "ainda que o autor se ocupe da representação histórica situada no século XVII, a questão principal não é a ficcionalização histórica, mas a crítica ao silenciamento histórico, à violência colonial, ao aplastamento cultural." (SANTOS, 2015, p. 79, tradução nossa). Permite, outrossim, que seja ampliada a reflexão à expansão da escravidão até os dias atuais na Angola independente. Esta famigerada repercussão histórica expressa-se nas mais diferentes modalidades: desde o tráfico de armas, diamante, petróleo, enfim, tudo o que representa o trabalho árduo e irregular a fim de manter uma ordem social regulada a partir de uma lógica opressora e excludente. "Desta lógica se destacam as imagens literárias de África, como espaço mítico para os que foram daí levados violentamente, enquanto símbolo de liberdade, e como espaço político e econômico relações comerciais entre europeus e africanos" (SANTOS, 2015, p. 80-81, tradução nossa).

Também como espaço mítico configura-se a África imaginada na obra do cubano Alejo Carpentier, $O$ reino deste mundo. Na trama, ambientada no Haiti do final do século XVIII, Santos relata que o resgate às raízes africanas é consumado através das crenças nos orixás e na prática do vodu, religião histórica do país. Essas práticas religiosas afirmam-se como valores identitários dentro da narrativa e assumem o propósito de resistência contra a escravidão física e cultural. Além disso, o contato com o mundo mítico é estabelecido através da presença de personagens históricos que atuam como representantes da África como legado ancestral e espaço lendário. O Haiti, neste sentido, desponta como alegoria do continente africano como um todo, através de "referências hiperbólicas que se descolam das imagens de África e que surgem na novela, legitimando-se como utopia de liberdade" (SANTOS, 2015, p. 106, tradução nossa).

A tradição oral, novamente presente, aparece na voz narrativa de Ti Noel, configurando-se como uma cadeia transmissora a quem cumpre o papel de preservação da memória local como "evocação máxima da cultura africana no imaginário do romance" (SANTOS, 2015, p. 115, tradução nossa)

A diegese ambienta-se entre 1791 e 1804, em plena Revolução Haitiana ou Revolta de São Domingos, como foi conhecida; caracterizou-se por treze anos de conflito brutal que culminaram na expulsão do governo colonial francês e 
na independência do país.Segundo a autora, o período é de suma importância, pois pode ser considerado um marco zero no contexto das mobilizações sociais sobre a identidade e a cultura negra. Ainda que não tenha conseguido desestruturar o sistema escravagista, a insurreição desestabilizou-o, pois evidenciou o descontentamento dos escravos com sua condição de trabalho e revelou a falácia da crença dos opressores na passividade dos subjugados.A trama, outrossim, possui o caráter de ficção historiográfica que revisita este passado a fim de problematizá-lo e de mostrar sua amplitude histórica. Santos considera que é essencial analisar esta obra sob a perspectiva africana, já que ainda que a fortuna crítica acerca dela seja numerosa, o assunto é pouco explorado a partir deste viés, e, quando é feito, não raro se percebem implícitos estereótipos que não ajudam a refletir sobre o tema.

Neste sentido, tanto a obra angolana quanto a cubana se assemelham e se singularizam, no sentido em que outorgam voz aos subalternizados pela história oficial através de narradores que cumprem o papel de griots evocadores da oralidade e propiciam a ampliação da discussão crítica acerca da opressão sofrida pelo negro.

Não se situa distante desta perspectiva a obra do colombiano Manuel Zapata Olivella. Assim como as anteriores, ela reelabora o contexto histórico oficial, restaurando o direito de enunciação pelos silenciados pela história. Nesta narrativa, o autor propõe um épico percurso dos africanos e seus descendentes desde sua origem. Propõe contar a trajetória do povo negro a partir de episódios significativos que constituem sua caminhada, como a Revolução do Haiti, a Inconfindência Mineira e o Movimento pelos Direitos Civis nos Estados Unidos, a fim de oferecer conotações que colocam em perspectiva diacrônica a questão da escravidão, trazendo a possibilidade de sua reelaboração nos dias atuais, através de outras nuances e matizes.

Santos afirma também que Changó, él gran putas se vale dos recursos de intertextualidade e de polifonia como fios condutores que funcionam como integradores deste mosaico de representação de acontecimentos que, ainda que encontrem-se espaçados na história, estão reunidos na construção imagética da(s) identidade(s) negroafricana(s).O primeiro artifício manifesta-se na interface entre personagens fictícios e fatos históricos, que dialogam na recriação deste percurso;já o segundo evidencia-se através de vozes de diferentes narradores. Estes, por sua vez, atuam personificados no imaginário mítico africano, repre- 
sentados por arquétipos como orixás, animais falantes, entes ancestrais e griots, entre outros. Por intermédio destas vozes narrativas, o discurso oral afirma-se, novamente, enquanto resgate da memória autóctone.

Representativa também é a estrutura simbólica de que se vale a narrativa, através da metáfora de um barco que,ao mesmo tempo em que parece embalar a história, remete à imagologia do navio negreiro. "O texto literário incita construções simbólicas, expressividades discursivas e representações que se assemelham a um barco em movimento." (SANTOS, 2015, p. 237).

A última das obras analisadas é a brasileira Um defeito de cor, de 2006.0 cenário no qual se ambienta a trama é o Brasil e a África do século XIX, com ênfase na Revolta dos Malês, na Bahia.

Mantendo o debate em torno da recuperação da identidade coletiva negroafricana e de reelaboração do passado histórico, a narrativa relata a vida de uma escrava, marcada por tragédia familiar, estupros, mortes, resiliência e superação. Desta vez, ademais de um narrador desprestigiado pela história temos uma voz feminina, o que lhe confere uma marginalização multiplicada: negra, mulher e escrava.

A trama de Ana Maria Gonçalves, destarte, singulariza-se por legitimar esta voz subalternizada pelos séculos de opressão colonial, racial, patriarcal e escravagista, permitindo que a experiência da escravidão seja narrada por quem a sofreu, devolvendo ao sujeito histórico calado pela história seu local de fala.

Santos propõe ainda pensar o Brasil metaforicamente, a partir da representação de arquétipos que sintetizariam a identidade nacional em diferentes momentos da literatura. Neste sentido, ela considera basilares as obras $O$ guarani (1857), de José de Alencar; A moreninha (1844), de Joaquim Manuel de Macedo; A escrava Isaura (1876), de Bernardo Guimarães; e Macunaíma (1928), de Mário de Andrade, enquanto ícones deste mosaico cultural. Ainda segundo a autora, esta seria uma forma de se pensar o Brasil a partir da justaposição de suas raízes fundacionais, considerando o processo de mestiçagem cultural e racial que nos define enquanto brasileiros.

Neste sentido, a obra de Ana Maria Gonçalves adquire uma perspectiva ainda mais significativa, pois outorga o protagonismo ao negro na história na contemporaneidade, instaurando um debate que se singulariza por legitimar a voz duplamente marginalizada da mulher negra, além de instigar a reconfiguração do 
imaginário branco hegemônico no nosso país, que por vezes ainda é sublimado na sociedade.

Ao refletir sobre a escravidão e seus reflexos na sociedade brasileira contemporânea, a autora também critica o que acredita ser uma visão romanceada da relação entre amo e escrava descrita pelo sociólogo Gilberto Freyre em Casa grande e senzala (1933). Podemos inferir que o preconceito em relação às muIheres negras e a tolerância ao racismo no Brasil podem ser observados diacronicamente; e que a visão disseminada por estudiosos como Freyre, de que os portugueses foram amistosos com os nativos e que a miscigenação teria sido um processo consentido, contribuiu para a manutenção do estereótipo atribuído à "mulata" na sociedade brasileira.

O estudo, portanto, legitima-se por oferecer-nos uma diversificada "visão negra da história" (SANTOS, 2015, p. 188, tradução nossa) ao analisar quatro obras de países cujas narrativas revelam contextos culturais e distintos que se coadunam na busca coletiva da(s) identidade(s) africana(s), em um processo de revisão historiográfica marcado pela crítica às conjunturas sociais, políticas e econômicas que serviram de alicerce à escravidão e que, até hoje, respaldam a exclusão do negro da sociedade.

\section{Referências}

CARPENTIER, Alejo. O reino deste mundo. Tradução Marcelo Tápia. São Paulo: Martins Fontes, 2009.

GONÇALVES, Ana Maria. Um defeito de cor.São Paulo: Record, 2006.

PEPETELA. A gloriosa família: o tempo dos flamengos. Lisboa: Dom Quixote, 1997.

SANTOS, Daiana Nascimento dos. El océano de fronteras invisibles: relecturas históricas sobre (¿el fin?de) la esclavitud en la novela contemporánea. Madrid: Editorial Verbum, 2015.

OLIVELLA, Manuel Zapata. Changó, el gran putas. Colombia: Oveja Negra, 1983. 